\title{
The value of taking an 'ethics history'
}

Gwen M Sayers, David Barratt, Catherine Gothard, Clive Onnie, Sunimalee Perera and Daniel Schulman Northwick Park Hospital, London

\begin{abstract}
Objectives-To study the value of taking an ethics history as a means of assessing patients' preferences for decision making and for their relatives' involvement. Design-Questionnaire administered by six junior doctors to 56 mentally competent patients, admitted into general and geriatric medical beds. Setting - A large district general hospital in the United Kingdom.

Main measures-To establish whether patients were adequately informed about their illness and whether they minded the information being communicated to their relatives. To establish their preference regarding truthful disclosure and participation in decision making with risk attached. To establish whether they wished to be involved in CPR decision making, and if not, who should make the decision. To establish whether they knew of living wills and whether they had any advance directives.

Results-Twenty-four (43\%) were inadequately informed of their illness. Forty-six (82\%) said they would want to know were something serious to be found. Twenty-eight (50\%) wanted to make their own decision if requiring risky treatment and 11 (20\%) wanted family members involved. Thirty-one (55\%) wanted to make a cardiopulmonary resuscitation (CPR) decision and five of these decisions differed from those made by the doctors. Twenty-five (45\%) preferred the doctors to decide. Eleven (20\%) of the patients had heard of living wills but only one had executed such a will. Seven (13\%) of the patients wished to provide advance directives. Three (5\%) did not find the history taking helpful but none were discomforted.

Conclusion-Taking an ethics history is a simple means of obtaining useful information about patients' preferences.

(Fournal of Medical Ethics 2001;27:114-117)
\end{abstract}

Keywords: Autonomy; confidentiality; CPR decisionmaking; advance directives

\section{Introduction}

Patient autonomy has for some time occupied a central position in the medical-ethical arena. ${ }^{1}$ In recognising the importance of autonomy it is acknowledged that patients have a right to self determination in matters involving their health care and that their wishes and values ought to be respected. However, complying with the principle of autonomy has always been tempered by the recognition that some patients may prefer not to make health care choices, some do not want to hear the truth about their health, and some might prefer others to act as their proxy.

In arguing the case for respecting patient variety, Brewin" $^{2}$ suggested that "What we need is better communication; more explanation for those who need it, less for those who don't; and greater empathy and understanding of the patient's real needs, fears, and aspirations".

This paper proposes that a simple means of addressing the issue can be found in extending the medical history to incorporate an ethics history. Such a history would inquire as to whether the patient required further information regarding his/ her condition. It would inform clinicians regarding the patient's attitude towards disclosure of information. It would explore his/her feelings as regards truth-telling and decision making, and inquire into whether he/she had any desire to participate in cardiopulmonary (CPR) decision making. Finally, it would establish whether he/she was in possession of a living will or had preference for any other form of advance directive.

Perhaps it is particularly opportune at this time to have such a measure of patient preference available, in the light of the recent adverse publicity centred on "not for resuscitation" orders in older patients. ${ }^{3}$ Not all elderly patients wish to make such decisions, ${ }^{4}$ and relatives in the UK cannot legally act as proxy decision makers. More importantly, not all elderly patients would wish their relatives to do so, ${ }^{45}$ and proxy predictions do not always accord with the patients' preferences. ${ }^{6}$

In America the federal government brought the patient Self-Determination Act into effect in 1991. This makes it obligatory for patients to be informed of their right to make decisions about their medical care. Nevertheless, the percentage of patients who execute advance directives is low. ${ }^{78}$ One of the reasons given is that patients prefer their doctors to initiate the discussion, ${ }^{9-11}$ but physicians appear reluctant to do so, ${ }^{12}$ although it is known that when such discussions do take place patients have benefited psychologically. ${ }^{13}$ Markson has suggested that the single most important barrier to such discussion is the doctor's lack of experience. ${ }^{14}$ Whatever the reasons, it is felt that all patients should at least be given the chance to have such conversations. ${ }^{15}$

\section{Methods}

Patients with a mental test score of $>8$ on an Abbreviated Mental Test ${ }^{16}$ were eligible for the study. 
There were no age limits to entry and ages ranged from 36 to 93, with a mean of 77 . However, only three patients under the age of 65 were included. Fifty-six patients (22 males and 34 females) were approached, and all consented to participate in the study. The histories were obtained by five senior house officers and one house officer, admitting the patients into either general medicine, or geriatric medicine, beds.

The patients were asked the following questions:

1. Do you know much about your illness?

2. Would you like further information?

3. If a member of your family approached us to find out what was wrong with you would you like us to tell them?

4. Do you think we should ask you first?

5. If something serious was wrong with you, would you want us to tell you (or someone else) or would you prefer not to know?

6. If you needed treatment or an operation, which was risky, would you want to know everything about it and decide what to do by yourself? If not who should decide?

7. Very occasionally patients have what is called a cardiac arrest. This means their heart stops beating. Usually we try to restart it using artificial respiration, drugs and sometimes an electric shock. Usually doctors decide what to do, but some patients prefer to decide for themselves. Would you like to make this decision? Would you like us or a family member to decide? Do you need more information before answering?

8. Some people make advance directives or living wills. Have you heard of this?

9. If so, are there any such directives that you would want us to know about?

10. Thank you for answering these questions. Do you think that discussing these issues has been helpful to you?

\section{Results}

Questioning the patients took about ten minutes and no difficulties were encountered.

\section{RESPONSES TO THE QUESTIONNAIRE}

Questions 1 and 2

Twenty-four $(43 \%)$ patients thought they were inadequately informed of their illness and requested further information, which was provided.

\section{Ouestion 3}

Fifty $(89 \%)$ were happy with their doctor discussing their illness with relatives without prior consultation with the patient.

One patient (suffering from cancer) said her illness should not be discussed with her relatives.

\section{Question 4}

Five patients said their relatives could be told, but that they would like to be asked first.
Question 5

Forty-six (82\%) of the patients said they would want to know the truth about their illness if something serious were to occur.

Four $(7 \%)$ patients said they would not want to be told.

One patient would not want to be told if there was no cure.

One patient said it depended. If he had "galloping cancer" he would not want to know.

One was unsure.

Three said they would want to be told together with a family member.

\section{Question 6}

Twenty-eight $(50 \%)$ of the patients said they would want to make their own decision if faced with the need for risky treatment. One of these patients stipulated that if incapacitated he would want his son to decide.

Seven $(12.5 \%)$ would want to make the decision together with family members.

Two $(3.5 \%)$ would want family members to decide.

Five $(9 \%)$ would want to make the decision together with the doctor.

Ten $(18 \%)$ would want the doctor to decide, one of whom requested his son be informed.

Two $(3.5 \%)$ would want the doctor to decide in conjunction with family members.

Two $(3.5 \%)$ were unsure.

\section{Question 7}

Thirty-one $(55 \%)$ patients said they would prefer to make their own CPR decision. One of these said he would want a doctor to decide only if he was unable to.

Five of the decisions made by the patients differed from those made by their doctors.

Twenty-five $(45 \%)$ said they would prefer the doctor to decide. None wanted their relatives to be involved

\section{Questions 8 and 9}

Eleven $(20 \%)$ patients said they had heard of living wills.

One patient said she had made such a will and the general practitioner held a copy. It stipulated that she did not want to be kept alive if there was no prospect of her recovering with a good quality of life.

Three of the patients who had heard of advance directives provided such directives in response to question 9: "If I'm ever a cabbage and on a life-support machine I would want it turned off"; "Not for resuscitation. I don't want to be kept going. I have been a member of the Euthanasia Society for the last six years. One has a right to decide when one wants to finish", and "I would not want to have active medical management if my brain was not functioning. I would not want to live if my leg was amputated as a result of gangrene."

Four of the patients who said they had not heard of advance directives provided directives after 
explanation: "I would not want to be left a vegetable with no quality of life"; "I would not want to be kept alive by a breathing machine"; "If my quality of life was such that I was not aware of things or was dependent, I would not want further treatment", and "I would not want to carry on if I was a vegetable".

\section{Question 10}

All but three patients (5\%) described the history taking as helpful.

Unsolicited comments included: "I think it is good that you are interested"; "Glad that my wishes are known"; "It helps the doctors have a better understanding of the patient"; "It gives the opportunity to open up and discuss general issues about one's life"; "The issues are important as doctors don't have the right to make all the decisions", "Doctors need to know what patients want"; "It puts my mind at rest"; "It enables my voice to be heard"; "It lets me have my say"; "Helped air some thoughts about my illness"; "Makes me feel more human", and "Nice to know that doctors care about what patients think".

\section{Discussion}

Information regarding the present illness was perceived by the patients to be inadequate in many cases, and taking the ethics history allowed those patients who so wished to be more fully informed.

Confidentiality would preclude providing information to relatives without expressly consulting the patient prior to such disclosure. However, the practicalities involved in geriatric medicine, and the frequency with which doctors are approached by relatives requesting information about the patient's condition, make it difficult for such consent to be routinely obtained. This study provides evidence supporting a general belief that most elderly people do not mind such information being divulged to relatives without obtaining prior consent. Nevertheless, it remains incumbent on the doctor to do so, and the ethics history provides a convenient means of obtaining such consent.

Most patients preferred to know the truth about their condition even though it might be serious, but some did not, and the history provided them with the opportunity to make such wishes known.

When it comes to CPR decision making our findings are similar to those of others, in that many of the patients preferred to make their own decision. What was most surprising, and unlike other studies, was that none wanted family members to be involved in the decision making, although about $20 \%$ wanted family members involved in decision making regarding "risky treatment".

Doyal and Wilsher, ${ }^{17}$ in proposing formal guidelines for withholding CPR, emphasise the fact that relatives have no legal rights in the treatment of adult patients and therefore, in the absence of knowledge of a patient's wishes, clinicians should decide a CPR status in "the best interests of the patient". However, they advise, for moral and evidential reasons, that discussions with relatives may be helpful if deemed appropriate by clinicians.

The argument for not involving relatives in such decision making stems from knowledge that surrogate decisions often differ from those made by patients, ${ }^{6}$ and that neither patients nor relatives agree regarding who should be consulted..$^{18}$ Different family members often disagree as to withholding of treatment, and one relative has believed that asking patients about their CPR preference is a form of covert euthanasia. ${ }^{19}$

A study comparing patients' and relatives' views on CPR decision making showed $45 \%$ of the patients wanting their relatives consulted..$^{20}$ Nevertheless, the conclusion drawn was that routine consultation with relatives was not indicated, provided the patients understood the implications of CPR decision making. In our study, the finding that none of the patients wanted their relatives involved in CPR decision making, may be because the CPR questions were couched among other varied questions and were not seen as being the only point of the questionnaire.

A prior study, which asked elderly patients specifically and only about their CPR preference, caused distress in some. ${ }^{21}$ The present study hoped to obviate such distress, by including CPR preferences amongst several other categories of preference. By so doing it was well received by $95 \%$ of the patients, and provided valuable information regarding those patients who expressed a CPR preference, and explicit consent to a clinician's decision by those patients who did not want to express a preference. In the context of such information, relatives' involvement in the decision making becomes peripheral.

Only one patient had made a living will, and we would have had no knowledge of this unless the history had been taken. In as much as these directives have legal standing in the $\mathrm{UK}^{22}{ }^{23}$ it is important for clinicians to be aware whether such documents exist.

Many patients commented positively on having been asked the questions. Their comments reflect current ethical thinking, such as their right to decide and the importance of doctors knowing what their patients want.

\section{Conclusion}

Taking an ethics history is a useful addendum to routine history taking, which may help both patients and clinicians when faced with difficult choices, particularly those involving value judgments. It allows for a rational approach to autonomy, by taking into account the understanding that not all patients want to make decisions for themselves. After all, making a choice that a doctor, or a family member decide in place of the patient, is an alternative expression of autonomy, far removed from the paternalism that still dogs the practice of medicine. 
Gwen M Sayers is Consultant Physician in Geriatric and General Medicine at Northwick Park Hospital, London. David Barratt, Clive Onnie, Sunimalee Perera and Daniel Schulman were all Senior House Officers, and Catherine Gothard was House Officer, at Northwick Park Hospital, London at the time of the study.

\section{References}

1 Angell M. Respecting the autonomy of competent patients. New England fournal of Medicine 1984; 310:1115-16.

2 Brewin TB. Truth, trust and paternalism. Lancet 1985;2 490-2. Ebrahim S. Do not resuscitate decisions. flogging dead horses or a dignified death? British Medical fournal 2000;320:1155-6.

4 Liddle J, Gilleard C, Neil A. The views of elderly patients and their relatives on cardiopulmonary resuscitation. Fournal of the Royal College of Physicians of London 1994;28:228-9.

5 Hill ME, MacQuillan G, Forsyth M, Heath DA. Cardiopulmonary resuscitation: who makes the decision? British Medical fournal 1994;308:1677.

6 Seckler AB, Meier DE, Mulvihill M, Cammer Paris BE Substituted judgement: how accurate are proxy predictions? Annals of Internal Medicine 1991:115:92-8.

7 Cox DM, Sachs GA. Advance directives and the Patient Self-Determination Act. Clinical Ethics 1994;10:431-43.

8 Gross MD. What do patients express as their preferences in advance directives? Archives of Internal Medicine 1998;158:363-

Lo B, McLeod GA, Saika G. Patient attitudes to discussing ife-sustaining treatment. Archives of Internal Medicine 1986, 146:1613-15

10 Kohn M, Menon G. Life prolongation: views of elderly outpatients and health care professionals. Fournal of the American Geriatrics Society 1988;36:840-4.

11 Reilly BM, Magnussen CR, Ross J, Ash J, Papa L, Wagner M. Can we talk? Inpatient discussions about advance directives in a community hospital. Archives of Internal Medicine 1994;154: 2299-308.

12 Morrison RS, Morrison EW, Glickman DF. Physician reluctance to discuss advance directives. An empiric investigation of potential barriers. Archives of Internal Medicine 1994:154:231118.

13 Markson LJ, Fanale J, Steel K, Kern D, Annas G. Implementing advance directives in the primary care setting. Archives of Internal medicine 1994;154:2321-7.

14 Kellogg FR, Crain M, Corwin J, Brickner PW. Life-sustaining interventions in frail elderly persons. Talking about choices. Archives of Internal Medicine 1992;152:3217-220.

15 Loewy E, Carlson RW. Talking, advance directives, and medical practice. Archives of Internal Medicine 1994;154:2265-7.

16 Hodkinson HM. Evaluation of a mental test score for assessment of mental impairment in the elderly. Age and Ageing 1972;1:233-8.

17 Doyal L, Wilsher D. Withholding cardiopulmonary resuscitation: proposals for formal guidelines. British Medical fournal 1993;306:1593-6.

18 Morgan R, King D, Prajapati C, Rowe J. Views of elderly patients and their relatives on cardiopulmonary resuscitation. British Medical fournal 1994;308:1677-8.

19 Heller A, Potter J, Sturgess I, Owen A, McCormack P. Resuscitation and patients' views. Questioning may be misunderstood by patients. British Medical fournal 1994;309:408.

20 Mead GE, Turnbull CJ. Cardiopulmonary resuscitation in the elderly: patients' and relatives' views. Fournal of Medical Ethics 1995;21:39-44.

21 Sayers GM, Schofield I, Aziz M. An analysis of CPR decision making by elderly patients. Fournal of Medical Ethics 1997;23: 207-12.

22 Stern K. Living wills in English law. Palliative Medicine 1993;7: 283-8

23 Luttrell S. Living wills do have legal effect provided certain criteria are met. British Medical fournal 1996;313:1148.

\section{News and notes}

\section{International Guidelines on Bioethics}

The Council for International Organizations of Medical Sciences (CIOMS) has published a booklet, International Guidelines on Bioethics, which provides an informal listing of selected international codes, declarations, guidelines, etc on medical ethics, bioethics, health care ethics and human rights aspects of health.
The listing is published as a supplement to The EFGCP News, Autumn 2000.

For copies and other information on EFGCP publications contact: F P Crawley, Editor, The EFGCP News, Schoolbergenstrat 47, B-3010 KesselLo, Belgium; fax: +32 163503 69; email: fpc@pandora.be 